RENEVEY-FRY (Chantal) (dir.). - En attendant le prince charmant. L'éducation des jeunes filles à Genève, 1740-1970

Genève : SRED, 1997. - 195 p.

Rebecca Rogers

URL : https://journals.openedition.org/histoire-education/438

DOI : $10.4000 /$ histoire-education.438

ISSN : 2102-5452

Éditeur

ENS Éditions

Édition imprimée

Date de publication : 1 janvier 2000

ISBN : 2-7342-0668-4

ISSN : 0221-6280

Référence électronique

Rebecca Rogers, «RENEVEY-FRY (Chantal) (dir.). - En attendant le prince charmant. L'éducation des jeunes filles à Genève, 1740-1970 », Histoire de l'éducation [En ligne], 85 | 2000, mis en ligne le 12 octobre 2008, consulté le 20 mai 2021. URL : http://journals.openedition.org/histoire-education/438 ; DOI : https://doi.org/10.4000/histoire-education.438

Ce document a été généré automatiquement le 20 mai 2021.

(c) Tous droits réservés 


\section{RENEVEY-FRY (Chantal) (dir.). - En attendant le prince charmant. L'éducation des jeunes filles à Genève, 1740-1970}

Genève : SRED, 1997. - 195 p.

Rebecca Rogers

\section{RÉFÉRENCE}

RENEVEY-FRY (Chantal) (dir.). - En attendant le prince charmant. L'éducation des jeunes filles à Genève, 1740-1970.- Genève : SRED, 1997. - $195 \mathrm{p}$.

1 Ce catalogue d'exposition offre à la fois un aperçu dans la longue durée des transformations de l'éducation féminine genevoise et un recueil de sources pour l'historien de l'éducation. Issu de la Communauté de Recherche Interdisciplinaire sur l'Éducation et l'Enfance (la CRIEE), cet ouvrage collectif ne prétend pas à l'exhaustivité mais propose plutôt « une réunion de matériaux pour servir à l'histoire de l'éducation des jeunes filles ». Se concentrant sur les «jeunes filles en fleurs", de l'âge de douze à dix-huit ans, les auteurs de ce petit volume attrayant proposent un tour d'horizon qui a le mérite de faire connaitre des sources et de donner les éléments pour une connaissance plus approfondie de l'éducation féminine.

2 L'ouvrage est divisé en cinq parties de longueur inégale. Une première intitulée "Comment les Lumières viennent aux filles" brosse un tableau rapide de la période moderne. L'étonnante précocité de l'alphabétisation féminine (avant la Révolution seules treize pour cent des femmes nées en ville demeurent illettrées) s'explique en partie par les efforts des notables; grâce à la Société pour faciliter l'instruction de la jeunesse, fondée en 1736, garçons et filles suivent un même programme. L'importance de la concurrence religieuse joue sans doute aussi en faveur de l'alphabétisation 
féminine avec la multiplication de couvents dans la ville. Enfin, les auteurs font l'hypothèse que le travail féminin, soit par le biais de l'apprentissage, soit par la domesticité a fourni des moyens pour l'instruction des jeunes filles pauvres. Plus novateur, sans doute, l'ouvrage propose une analyse et surtout de larges extraits de six journaux privés de jeunes filles. Le corpus est intéressant à la fois par son antériorité par rapport aux journaux français analysés par Philippe Lejeune, par la modernité de certains points de vue et par la richesse d'information sur leurs expériences éducatives. Les journaux considérés sont ceux d'Albertine Necker de Saussure, l'auteur de L'Éducation progressive, de Christine Romilly, fille d'un père pasteur, auteur d'articles de l'Encyclopédie, d'Amélie et Junie Odier, filles d'un magistrat et médecin très connu de la ville, de Germaine Necker, la future Madame de Staël, et de Caroline Lefort, fille d'un professeur de droit et homme d'État.

3 Les deux parties suivantes abordent, d'une façon contrastée, le développement de fondations philanthropiques au début du XIXe siècle, qui s'intéressent aux filles pauvres, orphelines, ou repenties et l'éducation privée de jeunes filles de la haute bourgeoisie à la fin du siècle. Les archives de trois internats donnent un aperçu fascinant de l'intérêt porté par les notables aux jeunes filles démunies. L'instruction rudimentaire et pratique de ces jeunes filles contraste évidemment beaucoup avec celle d'Émilie et d'Édith Gourd dont la correspondance regorge de détails concernant leur éducation à domicile et leurs leçons en ville.

4 Les quatrième et cinquième parties offrent une analyse plus terne et parfois difficile à suivre du développement institutionnel d'une éducation publique soutenue par l'État. La création en 1847 de l'École secondaire des jeunes filles (ESJF) offre le moyen pour les jeunes filles de poursuivre une éducation approfondie pour la période. On ne voit cependant pas clairement quel milieu social est vraiment concerné, ni quelles sont les conditions d'accès. L'ouverture en 1897 de l'École ménagère et professionnelle, en revanche, s'adresse clairement aux jeunes filles pauvres désirant acquérir une formation professionnelle. Au vingtième siècle, cette institution multiplie les apprentissages de couturière ou du dessin dans un but industriel et commercial, puis s'oriente vers la préparation à la carrière paramédicale. La comparaison fournie, à la fois avec le collège Calvin et l'école professionnelle des garçons, souligne les objectifs contrastés entre éducations féminine et masculine. Enfin, la dernière partie esquisse bien rapidement l'histoire de la mixité à Genève. Advenue dans le secondaire en 1969, celle-ci entraîne l'alignement des programmes de l'ESJF et du collège. Malgré cela, les auteurs concluent de manière pessimiste sur la réalité des progrès féminins constatant comme beaucoup que malgré la réussite scolaire des jeunes filles, les itinéraires féminins à l'université sont souvent décevants : «Les périodes de crise n'ont-elles pas toujours été prétexte à rouvrir le livre de comptes et à renvoyer Cendrillon à son foyer pour qu'elle y rêve au prince charmant?» (p. 188).

5 Il est à espérer que, la richesse des sources signalées dans ce catalogue stimule une synthèse plus universitaire sur l'éducation féminine genevoise qui manque toujours. Si les éléments d'une telle synthèse sont présents ici, l'effort pour penser les ruptures et les continuités est peu développé, comme d'ailleurs toute comparaison avec d'autres villes suisses ou les pays limitrophes. En particulier, la disparition de toute référence au contexte religieux dans l'analyse institutionnelle en quatrième partie étonne. Enfin, pour les lecteurs peu familiers avec le système éducatif suisse, les sections concernant la période contemporaine sont souvent peu claires. Mais étant donné les objectifs des 
auteurs, l'ouvrage réussit son pari. L'intérêt des documents et de l'iconographie incite à la réflexion et encourage les chercheurs à approfondir ce sujet. 